\title{
EC Driver - 41" Stroke Hydraulic Cylinder
}

\author{
Engineering Note \#3740.520-EN-254
}

Issued: May 24, 1990

Originator: Al Jaques

Checked: 
D-Zero Engineering Note

3740.520-EN-254

Issued $5 / 24 / 90$

\section{EC Driver - 41" Stroke Hydraulic Cylinder}

\section{Al Jaques}

It was decided to use a hydraulic cylinder resting on the floor of the argon spill trough in the EC carriage to drive the EC's motion on the center beam. Space was limited due to the spill bellows and their required support and containment system. The O.D. of the cylinder had to be limited to 3 to $3-1 / 2$ inches, maximum.

The weight of a wet EC and carriage is estimated to be 320 tons. The rolling coefficient of friction of the Tychoway rollers chosen to guide the EC and carriage along the hardened centerbeam ways is claimed to be less than 0.0025 . The driver will also need to overcome the forces produced by moving (rotating) the numerous bayonets located at the top of the cryostats in the many piping systems. These forces were conservatively estimated at $1000 \mathrm{lbs}$.

The drive force required to overcome these forces was then calculated to be:

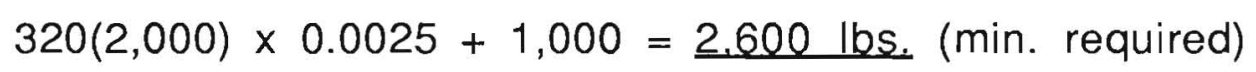

Due to the uncertainty in the actual roller coefficient of friction and the various unknowns in estimating the resistive forces contained in the piping and cabling systems attached to the cryostat, a conservative design factor of 5 was chosen. This should account for any uncertainty in our estimation of the minimum required drive force and also leaves us with a reserve to fall back on in case any unforeseen problems might arise. Thus the desired capacity of the driver was set at:

$$
(2,600) \times 5=\underline{13,000} \text { lbs. (design capacity) }
$$

Assuming a 3 inch O.D. cylinder with a $1 / 2$ inch wall (2 inch bore), we first analyzed a 1-3/8 inch diameter piston rod. Using Shigley \& Mischke's "Mechanical Engineering Design" (5th Ed.) and it's formulas for long columns with central loading, it was 
determined that a 1-3/8 inch diameter rod would not suffice, given our safety factor of 2 .

Increasing the piston rod diameter to $1-1 / 2$ inches proved to be sufficient. The maximum allowable load came out to be approximately $17,000 \mathrm{lbs}$., which is greater than the 13,000 lbs. design capacity.

With a 1-1/2 inch rod, a 2 inch bore and 10,000 psi capacity, the maximum return (retraction) force is:

$$
(\pi / 4)\left(2^{2}-1.5^{2}\right) \times(10,000)=\underline{13,744 \text { lbs. }} \text { (return force) }
$$

This meets the desired design capacity of the cylinder. On the extension of the cylinder, the pressure will be limited such to produce only the $13,000 \mathrm{lb}$. design capacity. Through the use of a regulator on the cylinder extension inlet, the pressure will be limited to:

$$
\begin{gathered}
13,000 /\left[(\pi / 4)(2)^{2}\right] \approx 4.200 \mathrm{psi} . \quad \text { (regulator setting) } \\
4,200 \times(\pi / 4)(2)^{2}=13.195 \mathrm{lbs} . \text { (thrust force) }
\end{gathered}
$$

Another reference used by some Fermi engineers in designing hydraulic cylinders is the "Design Engineers Handbook", Bulletin 0224-B1 published by the Parker-Hannifin Corporation. The piston rod-stroke selection table on page $b-5$ is used to determine the stroke factor. Our setup most approximates Case II of the table which gives a stroke factor of 0.70 . Multiplying this by the actual stroke (41") gives us a basic length of 28.7". Using the piston rodstroke selection graph on page b-6, the 1-1/2 inch rod and 28.7" basic length indicate an allowable thrust of approximately 13,000 Ibs. According to the Chief Application Engineer at the ParkerHannifin regional sales office in Des Plaines, IL, a minimum safety factor of 4 can be assumed in the piston rod-stroke selection graph, possibly even higher. This would be at least twice as high as our initial safety factor of 2 . Thus we feel our cylinder design falls well within the acceptable region of this reference. 
1.

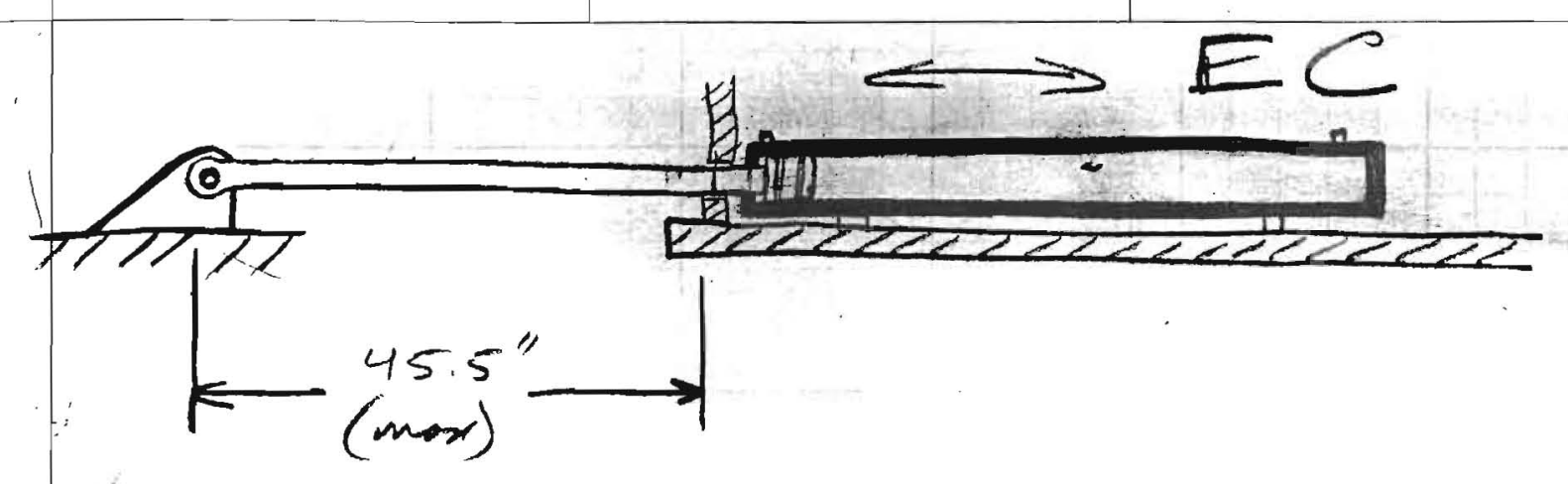

Column Loading (Medomical, Engiveanng Design, shigley śmischke, Sec. 3-14)

* first, assume a $13 / 8$ " $\phi$ piston rod

$$
\begin{aligned}
& I=\frac{\pi r^{4}}{4}=\varnothing .175 \mathrm{in}^{4} \\
& S_{y}=50,000 \mathrm{pse} \\
& \text { ( } \left.\begin{array}{c}
\min , \text { for piston } \\
\text { rod material }
\end{array}\right) \\
& E=29 e 6 \text { psi } \\
& C=1 . \varnothing \quad \text { (Table 3-3, p.123, "Roundal-rounded") } \\
& l=45.5 \mathrm{in} \\
& S_{f}=2 \text { (Safety factor) }
\end{aligned}
$$

$$
\begin{aligned}
& \left(\begin{array}{c}
\text { critical } \\
\text { load }
\end{array}\right) P_{c r}=\frac{C \pi^{2} E I}{l^{2}} \text { for a Euler column }
\end{aligned}
$$

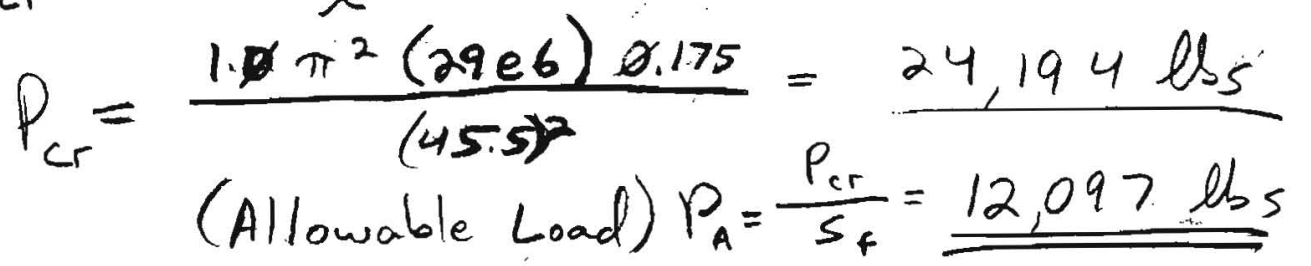

- check if column is a Euler Column (actual slenderness ratio) $\frac{l}{k}=\frac{45.5}{0.34375}=132.4$

$$
\begin{aligned}
K & =\text { radius of gyration } \\
& =\frac{d}{4}
\end{aligned}
$$

$\left(\begin{array}{c}\text { see } p \cdot 124 \\ \text { Fig. } 3-21\end{array}\right)$

$$
\begin{aligned}
\left(\frac{l}{k}\right)_{1} & =\left(\frac{2 \pi^{2} C E}{S_{y}}\right)^{1 / 2}=\left(\frac{\partial \pi^{2}(1.0) 29 e 6}{5 \phi, \phi \phi \phi}\right)^{1 / 2}=\underline{107 . \varnothing} \\
& \Rightarrow \frac{l}{k}>\left(\frac{l}{k}\right)_{1} \therefore \text { Euler Column }
\end{aligned}
$$


2.

Piston head diameter is 2". There extension forces of hydraulic ram is $P . A$ where $\rho=5, \varnothing \varnothing \varnothing$ psi and $A=\frac{\pi d^{2}}{4}$.

$$
F_{\max }=5 \phi \phi \phi\left(\frac{\pi(2)^{*}}{4}\right)=15,708 \mathrm{ls}
$$

max extension force on $\operatorname{rod}$ (column)

$F_{\text {max }}>P_{A}$ ie -must increase diameter

$$
\begin{aligned}
& -\operatorname{Try} d_{r d}=12^{\prime \prime} \\
& I=\frac{\pi r^{4}}{4}=0.249 \\
& P_{c r}=\frac{C \pi^{2} E I}{l^{2}}=\frac{1.0 \pi^{2}(29 e 6)(249)}{\left(45.5^{2}\right)^{2}} \\
& =34425 \mathrm{lls}_{s} \\
& P_{A}=\frac{P_{c r}}{s_{f}}=17213 \mathrm{llos}
\end{aligned}
$$

- check if column is still a Euler column

$$
\begin{aligned}
\frac{l}{k} & =\frac{45.5}{\left(\frac{1.5}{4}\right)}=\underline{121.3} \\
\rightarrow & \frac{l}{k}>\left(\frac{l}{k}\right)_{1} \therefore \text { Euler column }
\end{aligned}
$$

- Return (retracting) Force (10000 psi fluid on return)

$$
\begin{aligned}
F_{\text {ret }} & =10000\left[\frac{\pi}{4}\left(d_{\text {need }}^{2}-d_{\text {rod }}^{2}\right)\right] \\
& =10000\left(\frac{\pi}{4}\right)\left(2^{2}-1.5^{2}\right)=13,745 \mathrm{lths}
\end{aligned}
$$




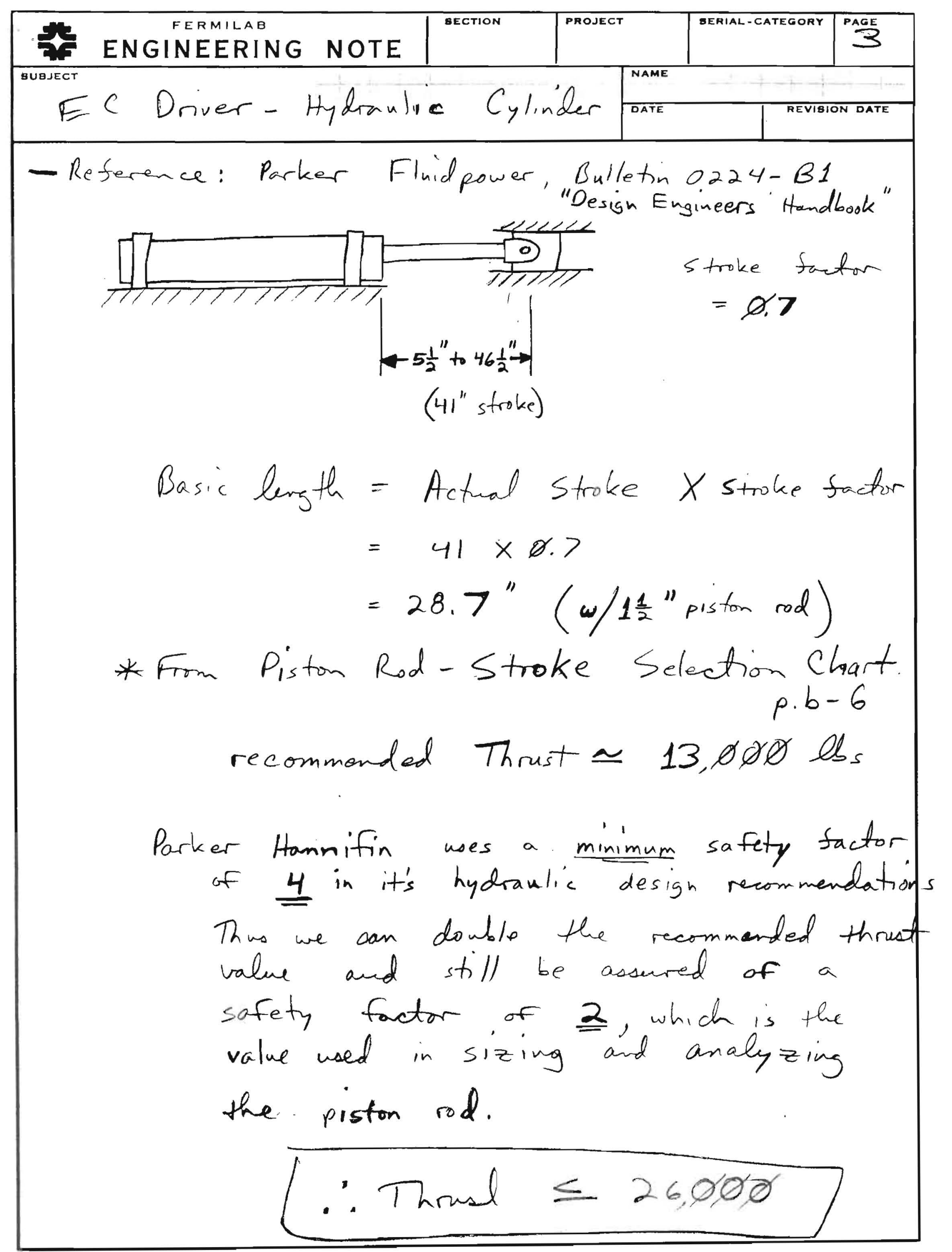




\section{i) $(\overrightarrow{\mathrm{s}})(\hat{\mathrm{c}}(\mathrm{C}) \mathrm{C})$,

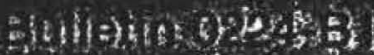
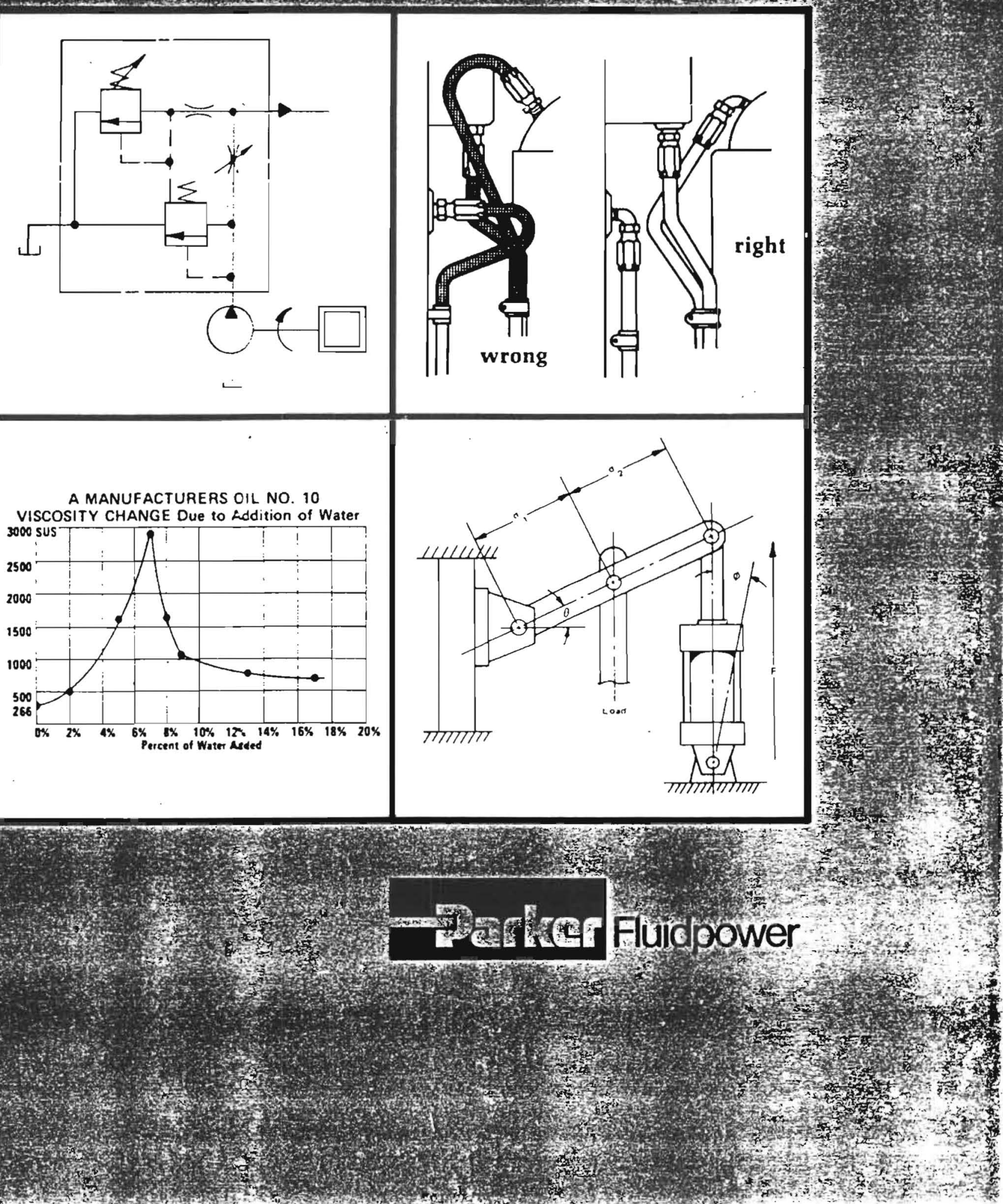


\section{mounting accessories}

A complete range of cylinder accessories are a vailable from most manufacturers to give versatility to present or future cylinder applications. These include (1) Eye Bracket, (2) Rod Clevis, (3) Pivot Pins, (4) Clevis Bracket and (S) Knuckle.

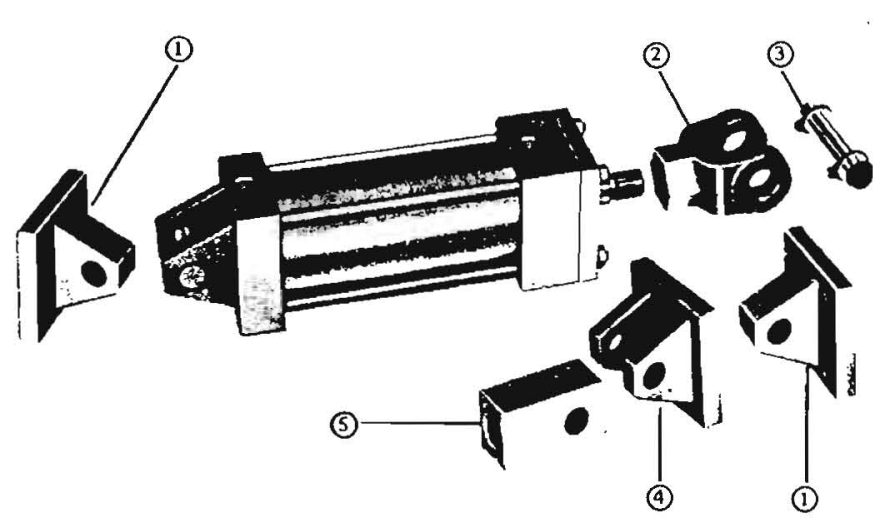

PH Industrial Cỵlinder with Accessories

illustration $b-2$

\section{mounting classes}

Standard mountings for power cylinders fall into two basic classes and three groups. The two classes can be summarized as follows:

Class 1 - Straight Line Force Transfer (Group 1 and 3 ).

Class 2 - Pivot Force Transfer (Group 2). Pivot mountings permit a cylinder to change its alignment in one plane.
Because a cylinder's mounting directly affects the maximum pressure at which the cylinder can be used, table b-3 (page b-4) should be helpful in the selection of the proper mounting for your application. Stroke length, piston rod connection to load, extra piston rod length over standard, etc., should be considered for thrust loads. Alloy steel mounting bolts are recommended for all mounting styles, and thrust keys are recommended for Group 3.

CYLINDER MOUNTING CLASSES

FOR CYLINDERS THAT ARE RECOMMENDED TO 3000 PSI WORKING AND 5000 PSI NON SHOCK SERVICE

\begin{tabular}{|c|c|c|c|}
\hline & CLASS 1 - GROUP 1 & CLASS 2 - GROUP 2 & CLASS 1 - GROUP 3 \\
\hline $\begin{array}{l}\text { HEAVY-DUTY SERVICE } \\
\text { For Thrust Loads - } \\
\text { For Tension Loads - }\end{array}$ & $\begin{array}{l}\text { FIXED MOUNTS which absorb } \\
\text { force on cylinder centerline. } \\
\text { Mig. Styles HB, TC, E } \\
\text { Mig. Styles JB, TB, E }\end{array}$ & $\begin{array}{l}\text { PIVOT MOUNTS which absorb } \\
\text { force on cylinder centerline. } \\
\text { Mtg. Styles DD, D, DB, BB } \\
\text { Mig. Styles BB, DD, D, DB }\end{array}$ & $\begin{array}{l}\text { FIXED MOUNTS which do not } \\
\text { absorb force on the centerline. } \\
\text { Mtg. Styles C, CP } \\
\text { Mtg. Styles C, CP }\end{array}$ \\
\hline $\begin{array}{l}\text { MEDIUM-DUTY SERVICE } \\
\text { For Thrust Loads - } \\
\text { For Tension Loads - }\end{array}$ & $\begin{array}{l}\text { Mtg. Styles H, JB } \\
\text { Mtg. Styles J, HB }\end{array}$ & - & $\begin{array}{l}\text { Mtg. Styles G, GP, F, FP } \\
\text { Mtg. Styles G, GP, F, FP }\end{array}$ \\
\hline $\begin{array}{l}\text { LIGHT-DUTY SERVICE } \\
\text { For Thrust Loads - } \\
\text { For Tension Loads - }\end{array}$ & $\begin{array}{l}\text { Mig. Style J } \\
\text { Mig. Style H }\end{array}$ & - & $\begin{array}{l}\text { Mtg. Styles CBP, CB } \\
\text { Mtg. Styles CBP, CB * }\end{array}$ \\
\hline
\end{tabular}

- Mounting style CB recommended for maximum pressure of 500 0.s.i. in short stroke applications (to 5 "). Longer strokes permit higher pressures. The use of a thrust key is recommended with this mounting. For more detatled information see manufacturer's product catalog. tabil: $h \cdot 3$

\section{cylinder stroke considerations}

Long Strokes - When considering the use of long stroke cylinders, it is necessary that the rod diameter be of such dimension so as to provide the necessary column strength. For tension (pull) loads, a correct rod size is easily selected by specifying cylinders with standard rod diameters, and using them at rated or lower pressures.

For compression (push) loads, the column 


\section{cylinder stroke considerations continued}

strength must be carefully considered. This involves the stroke length, the length of the piston rod extension, the support received from the rod end connection and gland and piston bearings, the style of mounting and the mounting attitude. It is also necessary to consider the bearing loads on pistons and glands, and to keep bearing pressures within proper limits by increasing the distance between piston and gland bearings. This is economically accomplished by various means. Commonly, separation of the bearings is effected with a stop tube on the piston rod much like a large diameter spacer sleeve. Other designs are provided according to the application requirements. The Stroke Selection Graph b-1, page b-6, printed in this handbook will guide you where requirements call for unusually long strokes, used in push applications.

When specifying cylinders with long stroke and stop tube, be sure to call out the net stroke and the length of the stop tube. Machine design can be continued without delay by laying in a cylinder equivalent in length to the Net Stroke Plus Stop Tube Length, which is referred to as Gross Stroke.

\section{piston rod compared to stroke}

\section{How to Use the Table}

The selection of a piston rod for thrust (push) conditions requires the following steps:

1. Determine the types of cylinder mounting slyle and rod end connection to be used. Then consult the table 4 [page b-5] and find the "stroke factor" that corresponds to the conditions used.

2. Using this stroke factor, determine the "basic length" from the equation:

Basic $=\begin{aligned} & \text { Actual } \\ & \text { Length }\end{aligned}$ Stroke
$28.7=41 \times .7$
Factor

\section{piston rod - stroke selection table}

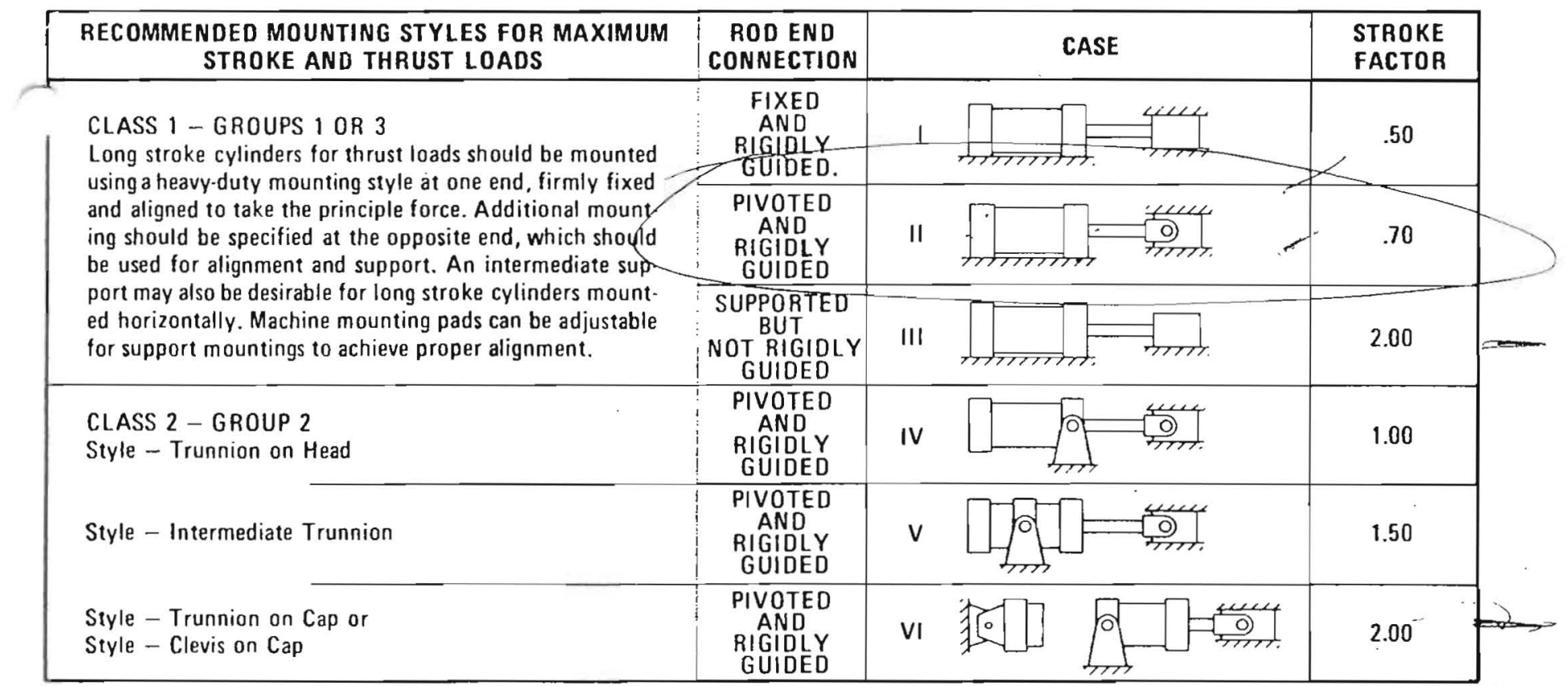

1... ble: $b-4$

Graph b-1, page b-6, is prepared for standard rod extensions beyond the face of the gland retainers. For rod extensions greater than standard, add the increase to the actual stroke in arriving at the "basic length."

3. Find the load imposed for the thrust applicatlion by multiplying the full bore area of the cylinder lyy the system pressure.

4. Enler the graph along the values of "basic length" and "thrust" as found above and note the point of intersection:

a. The correct piston rod size is read from the diagonally curved line labeled "Rod Diameter" next above the point of intersection.

b. The required lenglh of stop lube is read from the right of the graph by following the shaded band in which the point of intersection lies. 


\section{cylinder stroke considerations continued}

5. If required length of stop tube is in the region labeled "consult factory." submit the rollowing information for an individual analysis:

a. Cylinder mounting style.

b. Rod end connection and method of guiding load.

$$
\text { Safety factor }=4 \text { to } 1
$$

c. Bore required stroke, length of rod extension if greater than standard, and series of cylinder used.

d. Mounting position of cylinder.

Note: If al an angle or vertical. specify direction of piston rod.

e. Operating pressure of cylinder.

\section{PISTON ROD - STROKE SELECTION GRAPH}

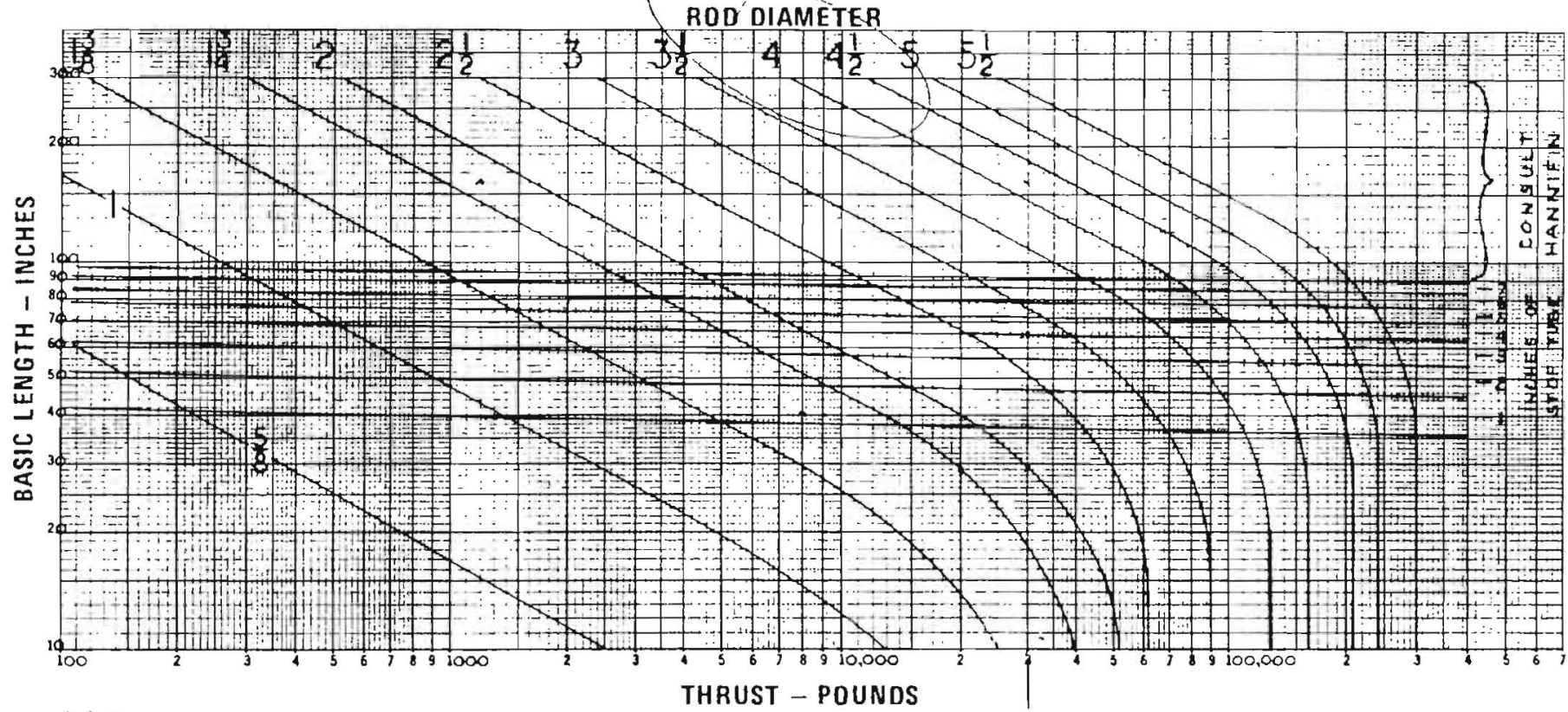

\section{determining acceleration and deceleration force for hydraulic cylinders}

The Uniform Acceleration Force Factor Graph and the accompanying formula can be used to rapidly determine the forces required to accelerate and decelerate a cylinder load. To determine these forces, the following factors must be known; total weight to be moved, maximum piston speed, distance available to start or stop the weight (load), direction of movement i.e. horizontal or vertical, and load friction. By use of the known factors and the "g" factor from graph 2, the force necessary to accelerate or decelerate a cylinder load may be found by solving the formula (as shown in graph on page b-7) applicable to given set of conditions.

\section{Nomenclature}

$V=$ Velocity in feet per minute

$\mathrm{S}=$ Distance in inches

$\mathrm{F}=$ Force in pounds

$W=$ Weight of load in pounds

$\mathrm{g}=$ Force factor

$\mathrm{f}=$ Friction of load on machine ways in pounds
To determine the force factor "g" from the graph, locate the intersection of the maximum piston velocity line and the line representing the available distance. Project downward to locate " $g$ " on the horizontal axis. To calculate the "g" factor for distances and velocities exceeding those shown on the chart, this formula can be used:

$$
\mathrm{g}=\frac{\mathrm{V}^{2}}{\mathrm{~S}} \times .0000517
$$

Example: Horizontal motion of a free moving 6.000 pound load is required with a distance of $1 / 2$ " to a maximum speed of 120 feet per minute. Formula (1) $\mathrm{F}=\mathrm{Wg}$ should be used.

$F=6,000$ pounds $\times 1.50($ from table $)=9,000$ pounds (page b-7)

Assuming a maximum available pump pressure of 1.000 p.s.i., a 4 " bore cylinder should be selected. operating on push stroke at approximately 750 p.s.i. pressure at the cylinder to allow for pressure losses from the pump to the cylinder. 